\title{
Evaluation of Lens Distortion by the Inverse Nodal Slide
}

\author{
Francis E. Washer and Walter R. Darling
}

(June 4, 1959)

\begin{abstract}
The evaluation of lens distortion by means of the inverse nodal slide method is discussed. The sources of error inherent in the method are investigated. Emphasis is given to the effect of asymmetric use of apertures. Measurements are reported on the same lens for which distortion values were measured by the direct nodal slide and photographic methods. A comparison of results obtained by the three different methods is given. It is concluded that accurate values of the distortion of a lens can be obtained by the inverse nodal slide method and that the precision of measurement is comparable to that of the two other methods mentioned when proper attention to sources of error is given.
\end{abstract}

\section{Introduction}

In the course of an extended investigation into the factors affecting the accuracy of measurements of lens distortion, a variety of ways were employed to facilitate the location of possible sources of error. In a previous paper, the values of distortion for a single lens by two different methods were reported [1]. ${ }^{1}$ These were designated methods $\mathrm{A}$ and B; $\mathrm{A}$ is photographic employing the precision lens testing camera [2], while $B$ is visual employing the nodal slide bench [3]. It was established that results comparable in accuracy and in good agreement could be obtained by either process provided proper consideration is given to various potential sources of error.

In this paper, a third manner of evaluating distortion is presented. This is a visual method that is essentially the reverse of the nodal slide method B. For that reason it is designated the inverse nodal slide method and is hereinafter referred to as method D. While this cannot be regarded as a new method, it is sufficiently different from A and B that it can be regarded as independent and so serve as a valuable check on the reliability of the values of distortion obtained by methods $\mathrm{A}$ and $\mathrm{B}$. In addition, it provides a process for determining quantitatively the effect of asymmetric use of apertures upon the measured values of distortion. This is an especially valuable feature as it is probable that errors from this source can and do occur in some of the diverse methods presently employed for the measurement of distortion.

To facilitate the comparison of the reliability of method D with methods $A$ and $B$, the values of distortion obtained by method D for wide angle lens No. 3 are contained in this article together with the results obtained on the same lens by A and B. This lens has a nominal focal length of 150 $\mathrm{mm}$, maximum aperture of $f / 6.3$, and a half-field angle of $45^{\circ}$.

It should also be mentioned for purposes of clarity that a method $\mathrm{C}$ was also developed and used in

\footnotetext{
1 Figures in brackets indicate the literature references at the end of this paper.
}

the course of this study. This differed from method $\mathrm{D}$ in that a larger aperture (4 in.) viewing telescope was used; and while fully as reliable as D, it was not as convenient to use in studying the effects of asymmetric use of apertures. For this reason detailed discussion of results obtained by method $\mathrm{C}$ is not reported.

\section{Inverse Nodal Slide Method}

In the direct nodal slide method, transverse linear displacements of the image formed in the image plane of the lens under test of an illuminated target located in the focal plane of the collimator are measured with the aid of a viewing microscope. In the inverse method, transverse angular displacements of the parallel beam of light emergent from the lens under test having a point source of light located in its focal plane are measured with the aid of a viewing telescope.

\subsection{Description of the Apparatus}

The optical T-bench (figs. 1 and 2) which is described in some detail in an earlier paper [4] is well suited to the measurement of distortion by the inverse nodal slide method. The lens under test is mounted in the nodal slide with its front facing the viewing telescope as shown in the figures. The illuminated target is mounted on a separate movable slide behind the lens. The viewing telescope has a full aperture of $40 \mathrm{~mm}$ and is mounted on a flexure plate fixture that permits precise pointing of the telescope at the target as seen through the lens. Micrometers on the flexure plate mounting permit the measurement of changes in the direction of pointing of the telescope.

\subsection{Method of Measurement}

In the inverse nodal slide method, a point source of light, or a properly illuminated reticle bearing well-defined cross lines, is initially placed at the focal point of the lens under test as shown in figure 1 . 


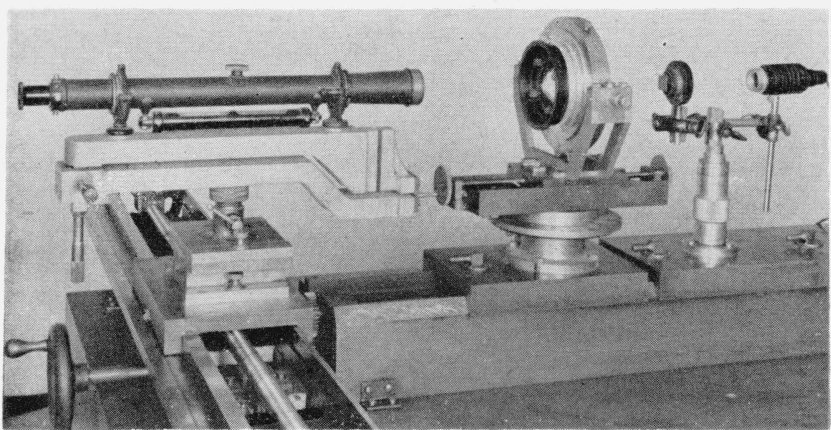

Figure 1. Photograph showing test equipment for method $D$ (axial condition).

The lens under test is shown mounted on the nodal slide in the center of the photograph. The illuminating system and target reticle are shown at the right behind the lens. The viewing telescope is shown at the left. It is equipped with micrometer adjustments to change its pointing and the whole assembly with micrometer adjustments to change its pointing and the whole

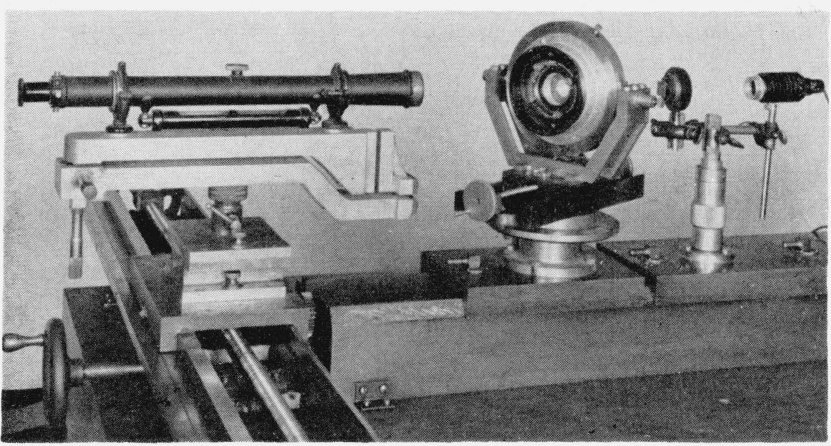

FIGURE 2. Photographs showing test equipment for method $D$ (off-axis condition).

The same equipment appearing in figure 1 is shown with the lens rotated about the vertical axis and the reticle displaced to maintain proper focus condition for extra-axial measurements.

This target is viewed through the front of the lens with a telescope focused for infinity. The lens is properly mounted in the nodal slide and so adjusted that small rotations of the lens about its vertical axis do not produce noticeable deviations of the emergent beam. (In the present work, if the point source of light is imaged on the crosshair of the viewing telescope and the image does not move when the lens is rotated about its vertical axis by amounts not exceeding $\pm 2 \mathrm{deg}$, the adjustment is satisfactory.) When this condition is present, the rear nodal point of the lens lies in the vertical axis of rotation of the nodal slide and the test may begin. To determine the distortion at angle $\beta$, the target reticle is moved away from the lens until the distance separating the rear nodal point of the lens and the point source is $f$ sec $\beta$. The lens is now rotated by an amount $+\beta$, and the pointing of the viewing telescope is changed by a micrometer until coincidence of its crosshairs with the image is achieved. The setting of the micrometer in scale divisions is read and recorded as $R$. The lens is now rotated through zero to $-\beta$ and similar pointings made with the reading recorded as $L$.
The values of radial distortion, $D_{\beta}$, for a given lens when determined by method A are fairly simply obtained from the following relation

$$
D_{\beta}=r-f \tan \beta \text {, }
$$

where $r$ is the measured distance on the negative from the axial point to the image of an infinitely distant object point lying in the direction marking angle $\beta$ with the axis of the objective and $f$ is the equivalent focal length of the objective. In the evaluation of distortion by method $\mathrm{D}$, the value of the radial distortion $D_{\beta}$ is given by the equation

$$
D_{\beta}=\frac{-k(R-L) f}{2 \cos ^{2} \beta},
$$

where $f$ is the equivalent focal length of the lens under test and $k$ is the constant of the micrometer in radians/scale division. The value of $k$ is known from previous calibrations to be $2.8323 \times 10^{-5}$ radians or $5.8421 \mathrm{sec}$ of arc per scale division. The terms $R$ and $L$ in eq (1) are the readings of the angle measuring micrometer in scale divisions. The values of $R$ and $L$ are measured with respect to an arbitrary zero which is the same for both; it is customary to select this arbitrary zero in such a manner that the values of $R$ and $L$ are approximately equal in magnitude but opposite in sign for comparable conditions of $+\beta$ and $-\beta$.

\subsection{Discussion}

When distortion is measured directly on the usual type of optical bench, the infinite object is provided by a large collimator that is well corrected for longitudinal spherical aberration. Consequently, there is usually no occasion to be concerned about whether or not the portion of the collimator aperture from which the parallel beam emerges is concentric with the axis of the collimator or displaced laterally therefrom. However, under the condition described in 2.2 , it is evident that the beam of collimated light emergent from the lens under test will usually be incident upon the objective of the viewing telescope in such a manner that asymmetric use of the telescope aperture will result. This belief was borne out by the first set of measurements from which were derived values of distortion so different from those obtained with the same lens by methods A and $B$ that they were initially believed to be valueless. This was particularly true for the larger values of $\beta$ where the clipping of both telescope and lens apertures was most pronounced. It therefore seemed worthwhile to make a study of these effects.

\section{Effect of Aperture on the Measured Values of Distortion}

It has long been known that asymmetric use of apertures can cause errors in telescope pointing [5]. Most of the discussion of this subject has been in the field of proper centering of sinall prisms on 
spectrometer tables, etc. In other fields, it has been customary to warn against asymmetric use of apertures when doing work of highest accuracy. There is, however, a dearth of publications dealing with the probable magnitudes of error from this source likely to be introduced when evaluating lens distortion. Accordingly, a series of careful measurements have been made which are herein reported.

\subsection{Method of Measurement of Aperture Effect}

As mentioned in section 2.1, method D is used on the T-bench. The lens and source are on the vertical arm of the $T$ and the viewing telescope is mounted on the crossbench. The telescope is pointed at right angles to the bench ways and the whole telescope assembly can be moved transversely across the emergent beam of the lens. The bench ways are quite straight so the pointing of the telescope is not affected by the transverse displacement. In making a set of measurements, such as shown in table 1 , the lens is rotated by amount $+\beta$, the telescope slide is moved to the left along its ways until no light from the target is seen through the telescope. The telescope slide is then moved slowly while viewing through it until the first faint image is seen. The reading of the bench scale for this point is recorded and noted as first image (F.I.). The telescope is then moved transversely

TABLE 1. Variation of distortion for $\beta=5^{\circ}$ with relative location of measuring aperture in the emergent beam for wide angle lens No. 3

The column, headed bench scale, gives the successive positions of the angle measuring telescope as its aperture is moved transversely across the beam emer gent from the test lens. The difference in telescope pointing is given in scale divisions, $R$ for $\beta=+5^{\circ}$ and $L$ for $\beta=-5^{\circ}$ (1 scale division $\left.=5.8421 \mathrm{sec}\right)$. $D_{R}$ and $D_{L}$ are the corresponding values of distortion, $D_{\beta}$ is the average value. The location of the center of the emergent beam is indicated by the underlined value of the bench scale. Part (a) shows the values of distortion with the telescope aperture set at $40 \mathrm{~mm}$ and part (b) shows similar information for the telescope aperture set at $8 \mathrm{~mm}$. Values of distortion are given in microns.

\begin{tabular}{|c|c|c|c|c|c|c|}
\hline $\begin{array}{l}\text { Bench } \\
\text { scale }\end{array}$ & $\begin{array}{l}R \text { scale } \\
\text { divisions }\end{array}$ & $D_{R}$ & $\begin{array}{l}\text { Bench } \\
\text { scale }\end{array}$ & $\begin{array}{c}L \text { scale } \\
\text { divisions }\end{array}$ & $D_{L}$ & $D_{\beta}$ \\
\hline \multicolumn{7}{|c|}{ (a) Telescope of $40-\mathrm{mm}$ aperture } \\
\hline $\begin{array}{l}m m \\
-0.7 \\
5 \\
10 \\
15 \\
20 \\
25\end{array}$ & $\begin{array}{r}\text { F. I. } \\
0.3 \\
-1.1 \\
-2.4 \\
-2.6 \\
-2.6\end{array}$ & $\begin{array}{r}-1 \\
5 \\
10 \\
11 \\
11\end{array}$ & \begin{tabular}{r}
\multicolumn{1}{c}{$m m$} \\
-1.7 \\
3.4 \\
8.4 \\
13.4 \\
18.4 \\
23.4
\end{tabular} & $\begin{array}{l}\text { F. I. } \\
1.4 \\
1.1 \\
1.5 \\
1.7 \\
2.4\end{array}$ & $\begin{array}{r}+6 \\
+5 \\
+6 \\
+7 \\
+10\end{array}$ & $\begin{array}{r}2 \\
5 \\
8 \\
9 \\
11\end{array}$ \\
\hline 30 & -2.6 & 11 & 28.4 & 2. 6 & +11 & 11 \\
\hline $\begin{array}{l}35 \\
40 \\
45 \\
50 \\
55 \\
60.7\end{array}$ & $\begin{array}{r}-2.2 \\
-2.2 \\
-2.2 \\
-2.2 \\
-1.3 \\
\text { L. I. }\end{array}$ & $\begin{array}{r}10 \\
10 \\
10 \\
10 \\
6 \\
\end{array}$ & $\begin{array}{l}33.4 \\
38.4 \\
43.4 \\
48.4 \\
53.4 \\
58.8\end{array}$ & $\begin{array}{l}2.6 \\
2.9 \\
3.8 \\
2.6 \\
3.9 \\
\text { L. I. }\end{array}$ & $\begin{array}{r}+11 \\
+13 \\
+16 \\
+11 \\
+17 \\
\end{array}$ & $\begin{array}{c}10 \\
11 \\
13 \\
10 \\
11 \\
-\end{array}$ \\
\hline \multicolumn{7}{|c|}{ (b) Telescope of 8-mm aperture } \\
\hline $\begin{array}{l}15.2 \\
20 \\
25\end{array}$ & $\begin{array}{r}\text { F. I. } \\
0.4 \\
-2.0\end{array}$ & -2 & $\begin{array}{l}13.6 \\
18.4 \\
23.4\end{array}$ & $\begin{array}{l}\text { F. I. } \\
2.4 \\
0.7\end{array}$ & $\begin{array}{l}+10 \\
+3\end{array}$ & $\begin{array}{l}4 \\
6\end{array}$ \\
\hline 30 & -2.4 & 10 & 28.4 & 2.4 & +10 & 10 \\
\hline $\begin{array}{l}35 \\
40 \\
44.8\end{array}$ & $\begin{array}{r}-3.3 \\
-1.3 \\
\text { L.I. }\end{array}$ & $\begin{array}{r}14 \\
6 \\
\end{array}$ & $\begin{array}{l}33.4 \\
38.4 \\
43.2\end{array}$ & $\begin{array}{r}2.5 \\
2.9 \\
\text { L. I. }\end{array}$ & $\begin{array}{r}+11 \\
+13 \\
\end{array}$ & $\begin{array}{r}13 \\
9 \\
\end{array}$ \\
\hline
\end{tabular}

along the bench until the image begins to disappear; this bench scale reading is recorded and noted as last image (L.I.). The midpoint of these two bench scale readings is assumed to be the proper setting for centered apertures of lens and telescope. The telescope is then set successively at $5-\mathrm{mm}$ intervals above and below this central reading of the bench scale (this center point is underlined in table 1) until the whole range for which the image can be seen is covered. Pointings of the telescope are read and recorded for each of these settings. The readings of the pointing micrometer are recorded under $\mathrm{R}$ for $+\beta$ and under $\mathrm{L}$ for $-\beta$. The same procedure is repeated with the telescope aperture reduced to $8 \mathrm{~mm}$. In order to give a clear picture of how the portions of the apertures are being used, the drawings shown in figure 3 and 4 were prepared. Figure 3 shows the relation of the cross section of the emergent beam from the lens and the telescope aperture for successive 5-mm displacements of the telescope assembly along its ways. This drawing is based on the displacements shown in table 1 for $\beta=+5^{\circ}$. It is to be noted that the cross section of the emergent beam from the lens is assumed to be still circular and that it remains stationary while the telescope aperture moves across it. The departure from a true circle is not significant at $5^{\circ}$,

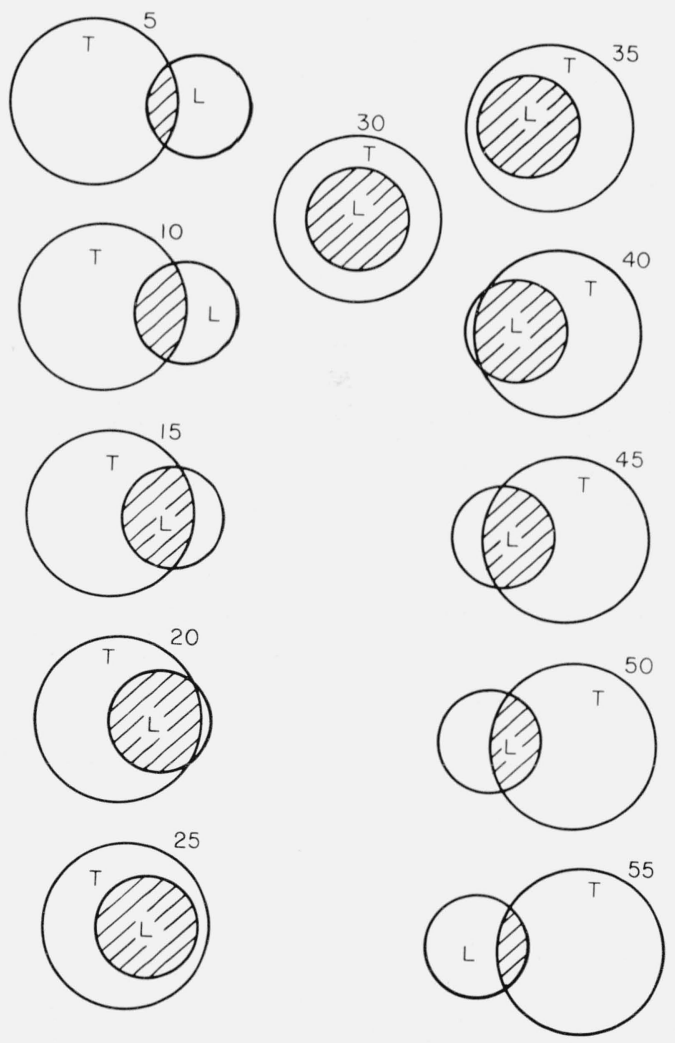

FIGURE 3. Sketches showing the relation of the cross section of the beam, L, emergent from the lens under test and the aperture, $T$, of the viewing telescope.

The shaded areas show the portion of the 40-mm telescope aperture being used. The numbers correspond to successive positions occupied by the telescope assembly and are the bench scale readings shown in table 1 (a) when determining 


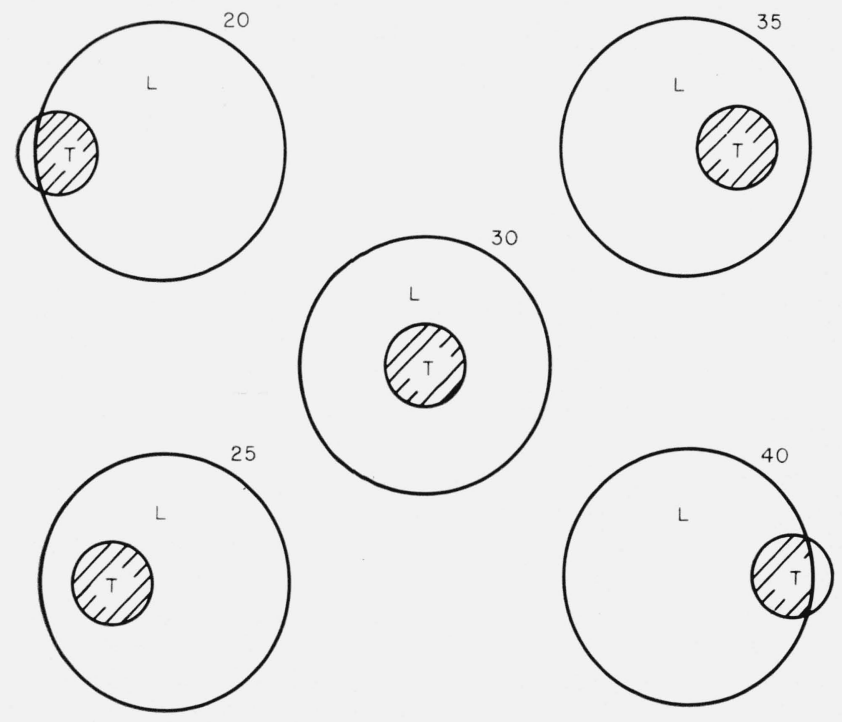

FIGURE 4. Sketches showing the relation of the cross section of the beam, L, emergent from the lens under test and the aperture, $\mathrm{T}$, of the viewing telescope.

The shaded areas show the portion of the $8-\mathrm{mm}$ telescope aperture being used and its relation to the total emergent beam from the lens. The numbers correspond to the bench scale readings in table 1(b) in the determination of $D_{R}$.

but at the larger angles of $\beta$ the transverse diameter is reduced in proportion to $\cos \beta$ and may be still further reduced at large values of $\beta$ because of vignetting by the lens mount.

While the value of the distortion $D_{\beta}$ is customarily computed with the aid of eq (1), this method of computing the values of $D_{\beta}$ does not lend itself readily to the determination of the effect of aperture. It is reasonable to assume that the most nearly correct value of distortion will be obtained when the exit aperture of the lens under test is centered with respect to the entrance aperture of the viewing telescope. However, when the lens is turned through the angle $\beta$ about its vertical axis, the center of the exit aperture of the lens is moved transversely by the amount $x_{\beta}$ where

$$
x_{\beta}=N_{p} \sin \beta,
$$

where $N_{p}$ is the distance separating the rear nodal point of the lens under test and the center of its exit aperture. This means that the telescope must be moved transversely by amount $2 x_{\beta}$ from the position properly occupied when measurements are made at angle $+\beta$ to the position properly occupied when measurements are made at angle - $\beta$. Even when this is done, it is possible for $R_{\beta}$ to differ in magnitude from $-L_{\beta}$ although the value of $D_{\beta}$ is still given correctly by eq (1). This condition does not necessarily reduce the reliability of the final values of $D_{\beta}$ as this dissimilarity of values of $R_{\beta}$ and $-L_{\beta}$ usually results from small misalinements of the viewing telescope or small transverse maladjustment of the rear nodal point of the lens with respect to the axis of rotation of the nodal slide. It can be shown that the presence of these maladjustments does not produce error in the accepted values of $D_{\beta}$.
However, for convenience in computations and graphing of results, it was decided to establish the zero of the micrometer at a point such that $R_{\beta}=-L_{\beta}$ for the condition of optimum reliability even though the telescope was moved transversely between the two determinations. With the zero so established it was then possible to evaluate the partial distortions $D_{R}$ and $D_{L}$ in a convenient manner.

The values of the partial distortions $D_{R}$ and $D_{L}$ are computed with the aid of the following relations:

$$
D_{R}=\frac{-k R f}{\cos ^{2} \beta}
$$

and

$$
D_{L}=\frac{+k L f}{\cos ^{2} \beta}
$$

and the final value $D_{\beta}$ is obtained from the relation

$$
D_{\beta}=\frac{D_{R}+D_{L}}{2},
$$

which is equivalent to the expression shown in eq (1). In table 1 , values of $D_{R}$ are shown for $\beta=5^{\circ}$ for each successive setting of the bench scale; the values of $D_{R}$ are also plotted in figure 5 . It is clear that the magnitude of $D_{R}$ varies with position of the viewing telescope along the bench scale. It is also clear that different portions of the apertures of lens and telescope are being used for each position. For the telescope of $40-\mathrm{mm}$ aperture, the value of $D_{R}$ (shown in box A of fig. 5) remains fairly constant during the middle part of the run but dips sharply at the extremes. It is probable that this effect arises from spherical aberration in the lens and telescope objective with the lens making the greater contribution. That the contribution of the lens is the greater is evident from consideration of the curve showing the values of $D_{R}$ (shown in box $\mathrm{B}$ of fig. 5) obtained when the telescope aperture is reduced to $8 \mathrm{~mm}$. The relation of the cross section of the emergent beam from the lens and the telescope aperture is shown in figure 4 . In this instance, the telescope aperture is so small that it is unlikely that spherical aberration in the telescope objective can produce appreciable error in pointing. Nonetheless, a comparable rise and fall of $D_{R}$ is evident at the start and finish of the traverse of the telescope aperture across the lens aperture.

While figures, comparable to figures 3 and 4 showing the relation of apertures in determining $D_{L}$, are not included in this report, it is obvious that they would look very similar to figures 3 and 4 . The values of $D_{L}$ are determined in the manner already described for $D_{R}$. The values of $D_{L}$ are shown in table 1 and are plotted in figure 5. Two methods are used in determining $D_{\beta}$. The first and preferred method is to average $D_{R}$ and $D_{L}$ with the aid of eq $(5)$ for comparable relative positions of the aperture. Values of $D_{\beta}$ by this method are shown in table 1. A second, but less sound method, is to average for identical settings of the bench scale. 

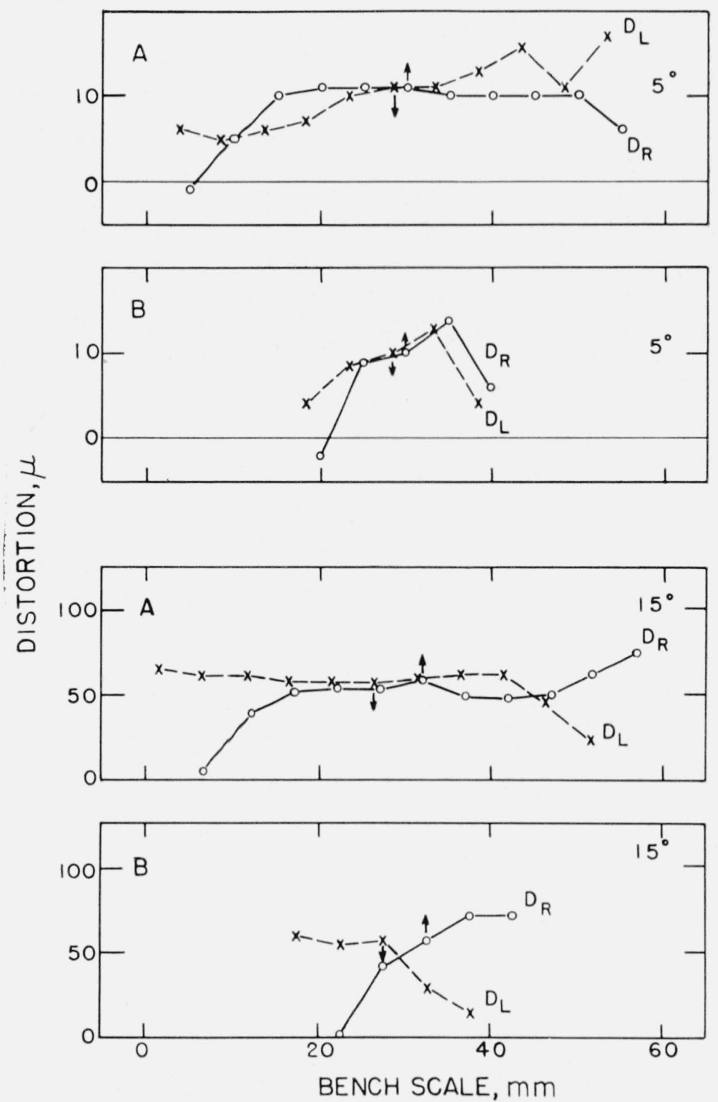

FiguRE 5. Variation of distortion, $D_{R}$ and $D_{L}$ as a function of transverse displacement of the viewing telescope with respect to the aperture of the lens under test.

The boxes designated A show values of $D_{R}$ and $D_{L}$ obtained with the viewing telescope of $40-\mathrm{mm}$ aperture for $\boldsymbol{\beta}=5^{\circ}$ and $15^{\circ}$. The upward pointing arrows attached to the circles mark the positions of centered apertures for the positive values of $\beta$; the downward pointing arrows attached to the crosses mark the positions of centered apertures for the minus values of $\beta$. The boxes designated $\mathrm{B}$ give like informat:on obtained with the viewing telescope of 8 -mm aperture for $\beta=5^{\circ}$ and $15^{\circ}$.

The foregoing procedures of determining $D_{R}, D_{L}$, and $D_{\beta}$ were repeated at successive values of $\beta$ ranging from $10^{\circ}$ to $45^{\circ}$ at $5^{\circ}$ intervals, and the values for $D_{\beta}$ for $\beta$ ranging from $5^{\circ}$ to $45^{\circ}$ are shown in table 2. The values of $D_{R}$ and $D_{L}$, obtained for $\beta=15^{\circ}, 30^{\circ}$, and $45^{\circ}$ are shown graphically in figures 5 and 6 . It is evident throughout this array that values of the distortion remain fairly constant in the center portions of the run and vary sharply at the extremes for the telescope with the 40 -mm aperture. On the other hand, the results obtained with the 8-mm aperture vary throughout the range of bench settings used. The center points for the various values of $\beta$ varied in location with respect to the bench scale as indicated by eq (2). For the four values of $\beta$ for which values of $D_{R}$ and $D_{L}$ are plotted, the short arrows in the figures mark the accepted center point for each run. It may be noted that their separations increase with increasing $\beta$. The values of the separations of aperture centers are shown under the heading $2 x_{\beta}$ in table 3 and are plotted as a function of $\sin \beta$ in figure 7 . It is evi-
TABLE 2. Variation of values of distortion in microns, $\mathrm{D}_{\beta}$ with relative location of the measuring aperture in the emergent beam for wide angle lens No. 3 for a series of values of $\beta$

Part (a) shows the variation of $D_{\beta}$ with separation, $h$, of the center of the measuring aperture with respect to the center of the emergent beam from the lens for a viewing telescope of 40 -mm aperture. Part (b) shows the results for similar measurements when the telescope aperture is reduced to $8 \mathrm{~mm}$.

\begin{tabular}{|c|c|c|c|c|c|c|c|c|}
\hline \multirow{2}{*}{$h$} & \multicolumn{8}{|c|}{ Variation of $D_{\beta}$ with $h$ for $\boldsymbol{\beta}=$} \\
\hline & $10^{\circ}$ & $15^{\circ}$ & $20^{\circ}$ & $25^{\circ}$ & $30^{\circ}$ & $35^{\circ}$ & $40^{\circ}$ & $45^{\circ}$ \\
\hline \multicolumn{9}{|c|}{ (a) Telescope of $40-\mathrm{mm}$ aperture } \\
\hline $\mathrm{mm}$ & & & & & & & & \\
\hline-25 & 15 & 35 & 66 & 106 & 161 & 212 & & \\
\hline-20 & 24 & 50 & 77 & 140 & 183 & 232 & 227 & 92 \\
\hline-15 & 27 & 56 & 92 & 146 & 198 & 240 & 234 & $\begin{array}{l}96 \\
96\end{array}$ \\
\hline $\begin{array}{l}-10 \\
-5\end{array}$ & $\begin{array}{l}29 \\
28\end{array}$ & $\begin{array}{l}56 \\
55\end{array}$ & $\begin{array}{l}96 \\
96\end{array}$ & $\begin{array}{l}148 \\
149\end{array}$ & $\begin{array}{l}199 \\
200\end{array}$ & $\begin{array}{l}241 \\
242\end{array}$ & $\begin{array}{l}235 \\
235\end{array}$ & $\begin{array}{l}96 \\
94\end{array}$ \\
\hline 0 & 30 & 58 & 99 & 149 & 201 & 240 & 235 & 91 \\
\hline 5 & 30 & 55 & 98 & 149 & 199 & 240 & 234 & 89 \\
\hline 10 & 29 & 55 & 97 & 146 & 198 & 243 & 234 & 94 \\
\hline 15 & 27 & 56 & 98 & 150 & 201 & 245 & 236 & 91 \\
\hline 20 & 25 & 55 & 90 & 138 & 206 & 251 & 244 & 91 \\
\hline 25 & 24 & 49 & 82 & 135 & 197 & 281 & -... & -- \\
\hline
\end{tabular}

(b) Telescope of 8-mm aperture

\begin{tabular}{r|c|c|c|c|c|c|c|c|}
\hline-10 & 13 & 31 & 59 & 103 & 162 & 232 & $-\overline{-}$ & $\overline{93}$ \\
-5 & 20 & 47 & 88 & 136 & 192 & 252 & 226 & \\
0 & 29 & 56 & 98 & 150 & 207 & 252 & 241 & 91 \\
5 & 27 & 50 & 87 & 142 & 208 & 253 & 240 & 98 \\
10 & 25 & 42 & 78 & 131 & 201 & --- & --- & -- \\
\hline
\end{tabular}

TABLE 3. Displacement of centers of apertures $2 x_{\beta}$, determined with telescope at $40-\mathrm{mm}$ aperture, of emergent beam from lens with rotation of lens about its rear nodal point as a function of angular separation from the axis

\begin{tabular}{|c|c|c|c|}
\hline \multirow{2}{*}{$\begin{array}{l}\text { Angular } \\
\text { separation } \\
\text { from axis }\end{array}$} & \multicolumn{2}{|c|}{ Bench scale } & \multirow{2}{*}{$\begin{array}{l}\text { Displace- } \\
\text { ment } 2 x_{\beta}\end{array}$} \\
\hline & Right & Left & \\
\hline $\begin{array}{r}\text { deg } \\
0 \\
5 \\
10 \\
15 \\
20\end{array}$ & $\begin{array}{l}m m \\
29.2 \\
30.0 \\
31.1 \\
32.0 \\
33.4\end{array}$ & $\begin{array}{l}m m \\
29.2 \\
28.4 \\
27.5 \\
26.5 \\
26.1\end{array}$ & $\begin{array}{c}m m \\
0.0 \\
1.6 \\
3.6 \\
5.5 \\
7.3\end{array}$ \\
\hline $\begin{array}{l}25 \\
30 \\
35 \\
40 \\
45\end{array}$ & $\begin{array}{l}33.7 \\
34.9 \\
36.0 \\
37.8 \\
40.6\end{array}$ & $\begin{array}{l}25.3 \\
24.4 \\
24.2 \\
23.4 \\
21.5\end{array}$ & $\begin{array}{r}8.4 \\
10.5 \\
11.8 \\
14.4 \\
19.1\end{array}$ \\
\hline
\end{tabular}

dent from the maximum value of $2 x_{\beta}$, that if the telescope were to remain permanently located at the position of optimum centering of lens and telescope apertures for $\beta=0$, the maximum aperture of the viewing telescope should be not less than the sum of $2 x_{\beta}$ and $d \cos _{\beta}$ where $d$ is the effective aperture of the lens under test. For the lens used in this experiment, the minimum acceptable aperture of the viewing telescope is $36.2 \mathrm{~mm}$.

This separation of the aperture centers as the lens is rotated about the vertical axis passing through the rear nodal point from $+\beta$ to $-\beta$ arises from the fact that there is an appreciable axial distance separating the rear nodal point and the plane of the entrance pupil of the lens. Consequently, the lens aperture moves from side to side and the light proceeding from it is incident upon the objective of the viewing 

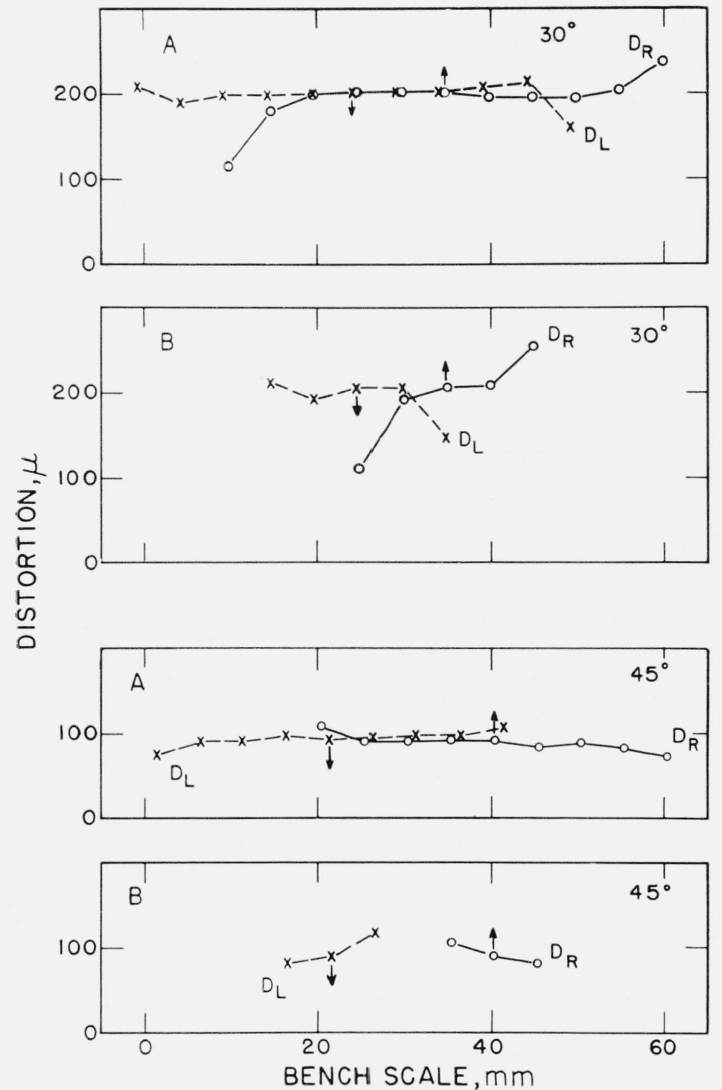

FIgure 6. Tariation of partial distortions $\mathrm{D}_{\mathrm{R}}$ and $\mathrm{D}_{\mathrm{L}}$ as a function of transverse displacement of the viewing telescope with respect to the aperture of the lens under test.

The boxes, designated $\mathrm{A}$, show values of $D_{R}$ and $D_{L}$ obtained with the viewing telescope of $40-\mathrm{mm}$ aperture for $\beta=30^{\circ}$ and $45^{\circ}$. The upward pointing arrows attached to the circles mark the positions of centered apertures for the positive values of $\beta$; the downward pointing arrows mark the positions of centered apervalues of $\boldsymbol{\beta}$; the downward pointing arrows mark the positions of centered aper-
tures $\mathbf{f}$ for the minus values of $\beta$. The boxes designated $\mathrm{B}$ give like information obtained with the viewing telescope of $8-\mathrm{mm}$ aperture for $\beta=30^{\circ}$ and $45^{\circ}$.

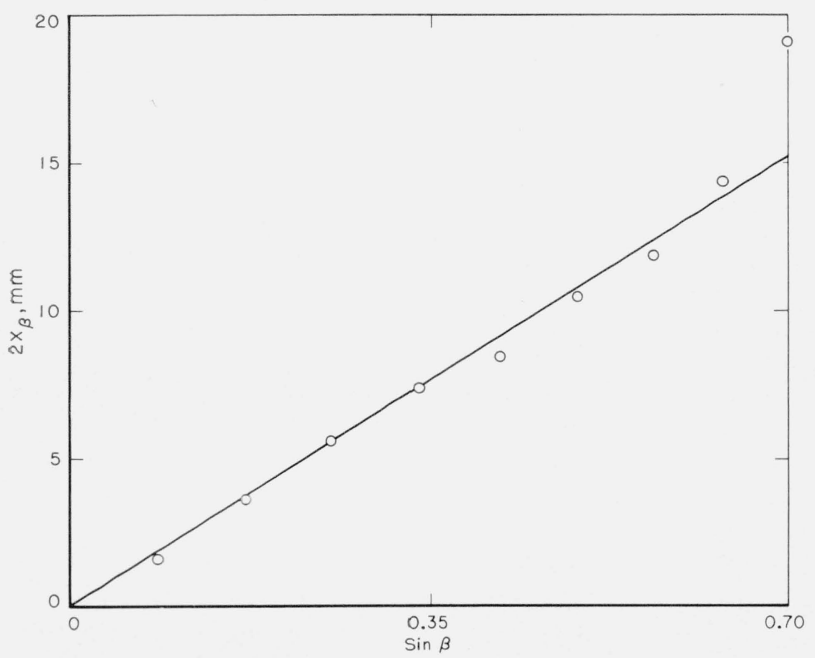

Figure 7. Measured separation of right and left aperture centers $2 \mathrm{x}_{\beta}$ as a function of $\sin \beta$.

For a rotation of the lens under test about a vertical axis passing through the rear nodal point, the position of the aperture center of the emergent beam for the setting $+\beta$ is separated from the position occupied by the same aperture center for the setting $-\beta$ by amount $2 x_{\beta}=N_{p} \sin \beta$, eq (2). telescope in a different region for each value of $\beta$. This effect is seen more clearly in figure 8 which shows a photograph of the lens aperture as seen in the exit pupil of the viewing telescope for successive settings of the lens $\beta= \pm 30^{\circ}$ and $\beta= \pm 45^{\circ}$. In making this photograph, the viewing telescope was made coaxial with the lens at $\beta=0$ so that the two apertures were centered with respect to each other. The viewing telescope was left fixed and the lens rotated to $+\beta$ and a photograph made. Without changing any adjustment of the camera or viewing telescope, the lens was rotated to $-\beta$ and a second exposure on the same camera film was made. Consequently, the figure shows the relative portions of the telescope aperture used under the two conditions. Unless the correction of the viewing telescope is

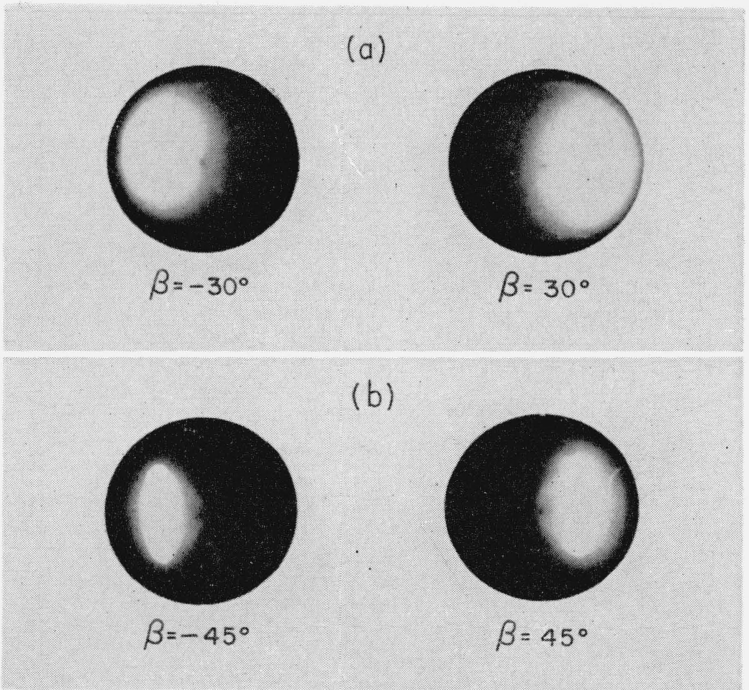

FIGURE 8. Photographs showing the appearance of the aperture of the lens under tests as seen in the exit pupil of the viewing telescope for two successive settings of the lens at (a) $\beta=+30^{\circ}$ and $\beta=-30^{\circ}$ and $(b) \beta=+45^{\circ}$ and $\beta=-45^{\circ}$.

The apertures of the lens and view ing telescope were centered initially at $\beta=0^{\circ}$ The position of the telescope remained fixed while the lens was rotated to the The position of the telescope remained fixed while the lens was rotated to the
successive positions. The dark circular area shows the exit pupil of the telescope while the light area shows the aperture of the lens under test.

excellent, it is evident that differing performance for the two areas can produce differences in the measured characteristics of the lens. In addition, it is also apparent that the lens aperture can be so far displaced with respect to the telescope aperture that partial obscuration can occur thus permitting the aberrations of the lens itself to make differing contributions with resultant errors in the final average values of distortion. To minimize the effect of unsymmetrical use of apertures, it is desirable that the aperture of the viewing telescope be sufficiently large that the cross section of the emergent beam from the lens shall at all times be within the boundaries of the aperture of the viewing telescope. Moreover, the objective of the viewing telescope should be excellently corrected over its entire area. In the present 
instance, the diameter of excellent correction should be not less than $37 \mathrm{~mm}$. It is questionable if this condition is satisfied by the objective of the viewing telescope used in this work for a diameter greater than $25 \mathrm{~mm}$.

\subsection{Effect of Incorrect Use of Aperture on Distortion Values}

In section 3.1, it was shown that appreciable variation in the values of $D_{R}$ and $D_{L}$ can be produced by the relative location of the cross section of the emergent beam from the lens within the aperture of the viewing telescope. It is of interest to determine the probable magnitude of the differences in the final values of the distortion that can be produced by the asymmetrical use of apertures. To determine this the maximum value of $D_{R}$ was paired with the maximum value of $D_{L}$ for each value of $\beta$ and a maximum value of $D_{\beta}$ for each value of $\beta$ was determined. These maximum values of $D_{\beta}$ are shown in table 4 under the heading $D_{E}$. In a similar manner, minimum values of $D_{R}$ and $D_{L}$ are paired to determine a minimum value of $D_{\beta}$ for each value of $\beta$. Finally, the centered values of $D_{R}$ and $D_{L}$ are paired to determine the most probable value of $D$. All of these combinations are listed in table 4 under the appropriate value of $D_{E}$ (the distortion referred to the equivalent focal length). The proper adjusting term to convert $D_{E}$ to distortion referred to the calibrated focal length $D_{C}$ is shown under the heading $\Delta D$. The results are also shown graphically in figure 9 where the various values of distortion,

TABLE 4. Extreme values of distortion in microns obtainable by possible combinations of the partial values of distortion, $D_{R}$ and $D_{L}$

The normal values for centered apertures are also shown. The value of dis tortion referred to the eguivalent focal length is $D_{E}$; the value of distortion referred to the calibrated focal length is $D_{C}$; and $\Delta D=\Delta F \tan \beta$, is the adjusting factor. Part (a) shows the values of the distortion with the telescope aperture factor. Part (a) shows the values of the distortion with the telescope aperture
set at $40 \mathrm{~mm}$ and part (b) shows similar information for the telescope aperture set at $40 \mathrm{~mm}$
set at $8 \mathrm{~mm}$.

\begin{tabular}{|c|c|c|c|c|c|c|c|c|c|}
\hline \multirow{3}{*}{$\begin{array}{l}\text { A ngular } \\
\text { separation } \\
\text { from axis }\end{array}$} & \multicolumn{3}{|c|}{ Maximum } & \multicolumn{3}{|c|}{ Minimum } & \multicolumn{3}{|c|}{ Normal } \\
\hline & $D_{E}$ & $\Delta D$ & $D_{C}$ & $D_{E}$ & $\Delta D$ & $D_{C}$ & $D_{B}$ & $\Delta D$ & $D_{C}$ \\
\hline & \multicolumn{9}{|c|}{ (a) Values of distortion with reasuring aperture of $40 \mathrm{~mm}$} \\
\hline deg & & & & & & & & & \\
\hline $\begin{array}{l}0 \\
5\end{array}$ & $\begin{array}{r}0 \\
14\end{array}$ & $\begin{array}{c}6 \\
20\end{array}$ & $\begin{array}{c}0 \\
-6\end{array}$ & $\begin{array}{l}0 \\
2\end{array}$ & $\begin{array}{r}0 \\
15\end{array}$ & $\begin{array}{r}0 \\
-13\end{array} \quad-100$ & $\begin{array}{r}0 \\
11\end{array}$ & $\begin{array}{r}0 \\
17\end{array}$ & $\begin{array}{r}0 \\
-6\end{array}$ \\
\hline 10 & 23 & 40 & -7 & 6 & 29 & $\begin{array}{l}-10 \\
-23\end{array}$ & $\begin{array}{l}11 \\
30\end{array}$ & $\begin{array}{l}14 \\
34\end{array}$ & $\begin{array}{l}-0 \\
-4\end{array}$ \\
\hline 15 & 70 & fo & -8 & 14 & 44 & -3 & 58 & 52 & 6 \\
\hline 20 & 114 & $8:$ & 31 & 35 & 60 & -25 & 99 & 71 & 28 \\
\hline 25 & 166 & 107 & 59 & 75 & 77 & -2 & 149 & 91 & 58 \\
\hline 30 & 223 & 132 & 91 & 137 & 95 & 42 & & 112 & 89 \\
\hline 35 & 281 & 160 & 121 & 206 & 116 & 9 & 240 & 136 & 104 \\
\hline \multirow{3}{*}{45} & 259 & 192 & 67 & 212 & 139 & 7 & 235 & 163 & 72 \\
\hline & 108 & 229 & -121 & 75 & 165 & -9 & 91 & 195 & -104 \\
\hline & \multicolumn{9}{|c|}{ (b) Values of distortion with measuring aperture of $8 \mathrm{~mm}$} \\
\hline 0 & 0 & 0 & 0 & 0 & 0 & 0 & 0 & 0 & \\
\hline & 14 & 20 & -6 & 1 & 15 & -14 & 11 & 18 & -7 \\
\hline 10 & 37 & 39 & -2 & 1 & 29 & $\begin{array}{l}11 \\
-28\end{array}$ & 29 & & -7 \\
\hline 15 & 66 & 50 & 7 & 7 & 44 & -37 & 56 & 54 & 2 \\
\hline 20 & 117 & 81 & 36 & 20 & 60 & -040 & 98 & 73 & 25 \\
\hline & 170 & 103 & 67 & 63 & 77 & -14 & 150 & 94 & 56 \\
\hline 30 & 234 & & 106 & $\begin{array}{l}129 \\
\end{array}$ & 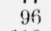 & 3 & 100 & 116 & 90 \\
\hline 35 & 266 & 15 & 111 & 20 & 11 & 85 & 25 & 141 & 111 \\
\hline 40 & 25 & 18 & & 215 & 139 & & 241 & 169 & 72 \\
\hline 45 & 111 & 222 & -111 & 81 & 166 & -85 & 91 & 202 & -111 \\
\hline
\end{tabular}

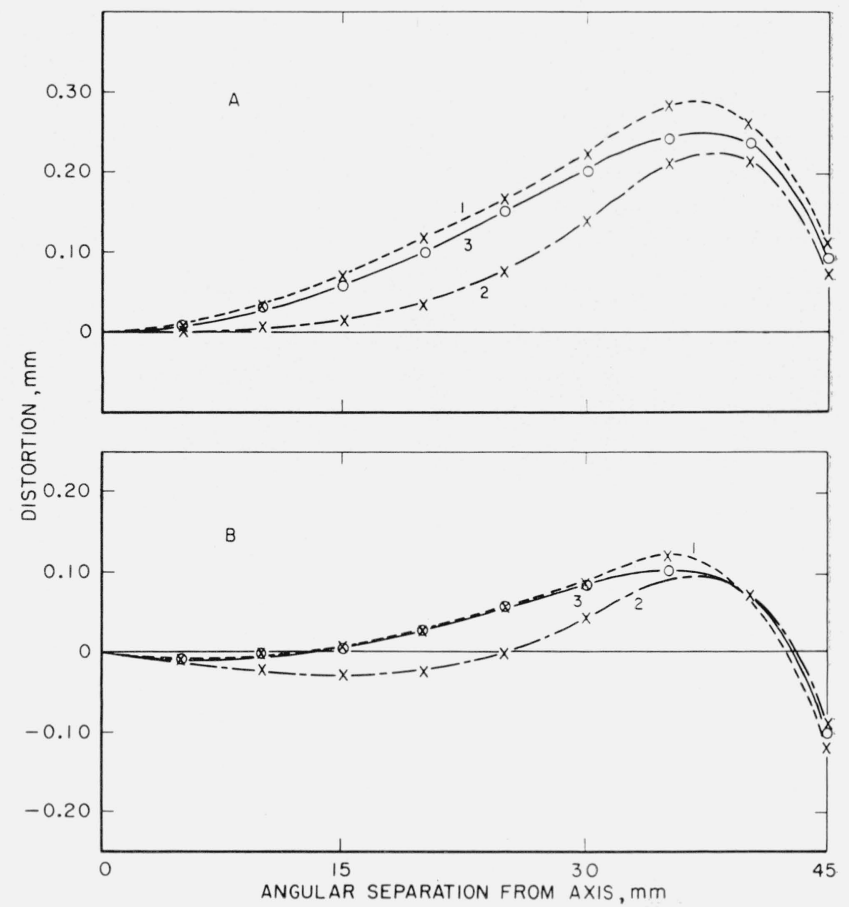

FIgure 9. Variation of distortion for incorrect and correct relative locations of the lens aperture with respect to the aperture of the viewing telescope as a function of angular separation $\beta$ from the axis.

The values of the distortion, $D_{E}$, referred to the equivalent focal length are shown in box $A$; the values of the distortion, $D_{C}$, referred to the calibrated focal length are shown in box B. The curves marked 1 show the maximum incorrect values obtained; the curves marked 2 show the minimum incorrect values; while values obtained; the curves marked 2 show the minimum incorrect values;
the curves, marked 3 , show the normal or correct values of the distortion.

$D_{E}$, are shown in box $\mathrm{A}$ and similar values of $D_{C}$ are shown in box B. The results for the $40-\mathrm{mm}$ measurng aperture alone are shown in the graph.

It is evident that strikingly large differences exist between the maximum and minimum values of distortion ranging as high as $90 \mu$ for $D_{E}$ and $60 \mu$ for $D_{c}$. It is, of course, unlikely that one would arrange the conditions of measurement to produce the values shown in curve 1 or 2 throughout the entire range but it is not unlikely that experimental conditions are frequently such that the experimenter obtains values nearer to those shown by curves 1 and 2 than those shown by curve 3 . The magnitude of the differences show how important it is that the relative positioning of test and measuring apertures be such as to minimize the possibility of errors arising from unsymmetrical use of apertures. It must be mentioned that while this study was made by the inverse nodal slide method, similar results could be obtained by improper use of the direct nodal slide method or any other method where asymmetrical use of apertures could occur.

\section{Evaluation of Distortion by Method D}

\subsection{Preliminary Remarks}

In the foregoing section, an important potential source of error in the measured values is described 
and the analysis leading to an evaluation of the possible magnitude of its contribution is discussed at length. On the basis of this study, the importance of well-centered apertures is emphasized. We are now ready to proceed to the evaluation of distortion for a given lens and to determine the precision of such measurements by method D.

\subsection{Results of Measurement}

Seven separate determinations of the values of the distortion were made on lens 3 using the centered aperture reading as far as possible in each instance. The results of measurement are listed in table 5 . The average for each value of $\beta$ and the departures from the average for each run are shown. Finally, the probable error for a single determination, $P E_{s}$ is shown for each value of $\beta$. It is clear that the precision indices in each case are satisfactorily low and compare favorably with values obtained by methods $\mathrm{A}$ and $\mathrm{B}$. The values of the distortion obtained by method D also compare favorably with values obtained by methods $A$ and $B$ as is shown in table 6 . The values of distortion obtained by methods $\mathrm{A}$ and $\mathrm{B}$ are taken from an earlier paper [1]. On considering the values of distortion listed in table 6 , it is clear that in only one instance is the difference between the values obtained by any of the three methods and the average as great as $5 \mu$. The average departure does not exceed $\pm 3 \mu$.

\section{Conclusion}

It is evident from the information contained in the foregoing section that the inverse nodal slide method

TABLE 5. Measured values of the distortion in microns, referred to the calibrated focal length, obtained for wide angle lens No. 3 by method D (visual inverse nodal slide method)

Seven separate determinations, their average, the departures from the average, and the probable error of a single determination $\left(P E_{s}\right)$ are shown.

\begin{tabular}{|c|c|c|c|c|c|c|c|c|}
\hline \multirow{2}{*}{$\begin{array}{c}\text { Angu- } \\
\text { lar } \\
\text { sepa- } \\
\text { ration } \\
\text { from } \\
\text { axis }\end{array}$} & \multicolumn{7}{|c|}{ (a) Values of distortion obtained from calibration } & \multirow{2}{*}{$\begin{array}{l}\text { Aver- } \\
\text { age for } \\
\text { seven }\end{array}$} \\
\hline & 1 & 2 & 3 & 4 & 5 & 6 & 7 & \\
\hline $\begin{array}{r}0 \\
5 \\
10 \\
15 \\
20\end{array}$ & $\begin{array}{r}0 \\
-6 \\
-4 \\
6 \\
28\end{array}$ & $\begin{array}{r}0 \\
-6 \\
-7 \\
5 \\
26\end{array}$ & $\begin{array}{r}0 \\
-5 \\
-7 \\
1 \\
25\end{array}$ & $\begin{array}{r}0 \\
-5 \\
-6 \\
4 \\
26\end{array}$ & $\begin{array}{r}0 \\
-6 \\
-7 \\
5 \\
24\end{array}$ & $\begin{array}{r}0 \\
-5 \\
-7 \\
2 \\
26\end{array}$ & $\begin{array}{r}0 \\
-5 \\
-6 \\
3 \\
28\end{array}$ & $\begin{array}{r}0 \\
-5 \\
-6 \\
4 \\
26\end{array}$ \\
\hline $\begin{array}{l}25 \\
30 \\
35 \\
40 \\
45\end{array}$ & $\begin{array}{r}58 \\
89 \\
104 \\
72 \\
-104\end{array}$ & $\begin{array}{r}59 \\
94 \\
103 \\
78 \\
-103\end{array}$ & $\begin{array}{r}57 \\
87 \\
108 \\
78 \\
-108\end{array}$ & $\begin{array}{r}61 \\
93 \\
113 \\
80 \\
-113\end{array}$ & $\begin{array}{r}58 \\
87 \\
109 \\
78 \\
-109\end{array}$ & $\begin{array}{r}57 \\
90 \\
112 \\
76 \\
-112\end{array}$ & $\begin{array}{r}58 \\
91 \\
109 \\
76 \\
-109\end{array}$ & $\begin{array}{r}58 \\
90 \\
108 \\
77 \\
-108\end{array}$ \\
\hline & \multicolumn{7}{|c|}{ (b) Departures from the average for calibration } & \\
\hline & 1 & 2 & 3 & 4 & 5 & 6 & 7 & \\
\hline $\begin{array}{r}0 \\
5 \\
10 \\
15 \\
20\end{array}$ & $\begin{array}{r}0 \\
-1 \\
2 \\
2 \\
2\end{array}$ & $\begin{array}{r}0 \\
-1 \\
-1 \\
1 \\
0\end{array}$ & $\begin{array}{r}0 \\
0 \\
-1 \\
-3 \\
-1\end{array}$ & $\begin{array}{l}0 \\
0 \\
0 \\
0 \\
0\end{array}$ & $\begin{array}{r}0 \\
-1 \\
-1 \\
1 \\
-2\end{array}$ & $\begin{array}{r}0 \\
0 \\
-1 \\
-2 \\
0\end{array}$ & $\begin{array}{r}0 \\
0 \\
0 \\
-1 \\
2\end{array}$ & $\begin{array}{r} \pm 0 \\
0 \\
1 \\
1 \\
1\end{array}$ \\
\hline $\begin{array}{l}25 \\
30 \\
35 \\
40 \\
45\end{array}$ & $\begin{array}{r}0 \\
-1 \\
-4 \\
-5 \\
4\end{array}$ & $\begin{array}{r}1 \\
4 \\
-5 \\
1 \\
5\end{array}$ & $\begin{array}{r}-1 \\
-3 \\
0 \\
1 \\
0\end{array}$ & $\begin{array}{r}3 \\
3 \\
5 \\
3 \\
-5\end{array}$ & $\begin{array}{r}0 \\
-3 \\
1 \\
1 \\
-1\end{array}$ & $\begin{array}{r}-1 \\
0 \\
4 \\
-1 \\
-4\end{array}$ & $\begin{array}{r}0 \\
1 \\
1 \\
-1 \\
-1\end{array}$ & $\begin{array}{l}1 \\
2 \\
3 \\
2 \\
3\end{array}$ \\
\hline
\end{tabular}

TABLE 6. Comparison of the values of distortion $\mathrm{D}_{\mathrm{D}}$ obtained by the inverse nodal slide method with values of distortion $\mathrm{D}_{\mathrm{A}}$ and $\mathrm{D}_{\mathrm{B}}$ for the same lens obtained by the precision lens testing camera and the direct nodal slide

Part (a) shows the measured values of the distortion obtained by methods A $\mathrm{B}$, and $\mathrm{D}$ and their average. Part (b) shows the departures from the average for each method and the average departure for any of the three methods. All values are given in microns.

\begin{tabular}{|c|c|c|c|c|}
\hline \multirow{2}{*}{$\begin{array}{l}\text { Angular } \\
\text { separation } \\
\text { from axis }\end{array}$} & \multicolumn{3}{|c|}{$\begin{array}{l}\text { (a) Values of distortion obtained } \\
\text { by method }\end{array}$} & \multirow{2}{*}{$\begin{array}{l}\text { A verage } \\
\text { for the } \\
\text { three }\end{array}$} \\
\hline & A & B & $\mathrm{D}$ & \\
\hline $\begin{array}{r}\text { deg } \\
0 \\
5 \\
10 \\
15 \\
20\end{array}$ & $\begin{array}{r}0 \\
-5 \\
-5 \\
4 \\
21\end{array}$ & $\begin{array}{r}0 \\
-7 \\
-8 \\
1 \\
21\end{array}$ & $\begin{array}{r}0 \\
-5 \\
-6 \\
4 \\
26\end{array}$ & $\begin{array}{r}0 \\
-6 \\
-6 \\
3 \\
23\end{array}$ \\
\hline $\begin{array}{l}25 \\
30 \\
35 \\
40 \\
45\end{array}$ & $\begin{array}{r}49 \\
82 \\
113 \\
79 \\
-113\end{array}$ & $\begin{array}{r}52 \\
87 \\
106 \\
79 \\
-106\end{array}$ & $\begin{array}{r}58 \\
90 \\
108 \\
77 \\
-108\end{array}$ & $\begin{array}{r}53 \\
86 \\
109 \\
78 \\
-109\end{array}$ \\
\hline \multirow{2}{*}{$\begin{array}{l}40 \\
45\end{array}$} & \multicolumn{3}{|c|}{$\begin{array}{l}\text { (b) Departures from the average } \\
\text { for method }\end{array}$} & \\
\hline & A & B & $\mathrm{D}$ & \\
\hline $\begin{array}{r}0 \\
5 \\
10 \\
15 \\
20\end{array}$ & $\begin{array}{r}0 \\
1 \\
1 \\
1 \\
-2\end{array}$ & $\begin{array}{r}0 \\
-1 \\
-2 \\
-2 \\
-2\end{array}$ & $\begin{array}{l}0 \\
1 \\
0 \\
1 \\
3\end{array}$ & \\
\hline $\begin{array}{l}25 \\
30 \\
35 \\
40 \\
45\end{array}$ & $\begin{array}{r}-4 \\
-4 \\
4 \\
1 \\
-4\end{array}$ & $\begin{array}{r}-1 \\
1 \\
-3 \\
1 \\
3\end{array}$ & $\begin{array}{r}5 \\
4 \\
-1 \\
-1 \\
1\end{array}$ & \\
\hline
\end{tabular}

is satisfactory for use in the evaluation of distortion provided that care is taken to insure the symmetric use of apertures. Further experiments were also made using a larger telescope having a clear aperture of 4 in. and an objective well corrected for spherical aberration. With this larger telescope, it was not necessary to traverse the telescope mount sidewise to center the aperture. The values of distortion obtained with this larger telescope were essentially the same as those obtained with the $40-\mathrm{mm}$ centered telescope and so are not herein reported.

The authors express their appreciation to Mr. E. C. Watts who made the drawings that appear in this article.

\section{References}

[1] F. E. Washer, W. P. Tayman, and W. R. Darling, Evaluation of lens distortion by visual and photographic methods, J. Research NBS 61, 509 (1958) RP2920.

[2] I. C. Gardner and F. A. Case, Precision camera for testing lenses, J. Research NBS 18, 449 (1937) RP984.

[3] A. H. Bennett, The distortion of some typical photographic objectives, J. Opt. Soc. Am. and Rev. Sci. Instr. 14, 245 (1927).

[4] F. E. Washer, Optical T-bench method of measuring longitudinal spherical aberration, J. Research NBS 61, 31 (1958) RP2880.

[5] L. W. Tilton, Permissible curvature of prism surfaces and inaccuracy of collimation in precise minimum-deviation refractometry, J. Research NBS 11, 25 (1933) RP575.

Washington, D.C.

(Paper 63C2-13) 